\title{
The influence of irradiation by electrons and $\gamma$-quanta on photoelectrical and optical properties of epitaxial $\mathrm{Pb}_{1-\mathrm{x}} \mathrm{Mn} \mathrm{n}_{\mathrm{x}}$ Te film
}

\author{
Sh.M. Abbasov ${ }^{1}$, I.R. Nuruyev ${ }^{2}$, T.B. Tagiyev $^{2}$, G.T. Agaverdiyeva ${ }^{1}$, T.I. Kerimova ${ }^{1}$, G.T. Ismayilova ${ }^{2}$ \\ ${ }^{1}$ Institute of Radiation Problems, Azerbaijan NAS \\ ${ }^{2}$ Institute of Physics, Azerbaijan NAS \\ Phone: (+99412)4 393-391; fax(+99412) 4398-318; e-mail: shabbasov@rambler.ru
}

\begin{abstract}
We have studied the effect of electron irradiation on photoelectrical and optical properties of $\mathrm{Pb}_{1-\mathrm{x}} \mathrm{Mn}_{\mathrm{x}} \mathrm{Te}(0.01 \leq x \leq 0.05)$ epitaxial films containing $0.5 \ldots 1$ at. $\%$ of gallium with thicknesses of $1 \ldots .5 \mu \mathrm{m}$, obtained by the method of molecular beam epitaxy on substrates $\mathrm{BaF}_{2}$ (III).
\end{abstract}

Keywords: epitaxial film, energy of electrons, $\gamma$-quanta, optical absorption.

Manuscript received 10.03.07; accepted for publication 24.04.07; published online 19.10.07.

\section{Introduction}

Recent years, the epitaxial films of indicated solid solutions obtained on different substrates widely draw the attention of researchers and are intensively studied [1-3].

As known, in order to create various devices of IR technique, multielement matrices, IR-photodetectors and to ensure their successful application in modern optoelectronics, it is necessary to obtain films with stable composition, perfect structure, and predetermined reproducible electrophysical, photoelectrical, and optical properties.

\section{Experimental}

Here, we present the results of experimental investigations of the influence of $\gamma$-irradiation on infrared photosensitivity of epitaxial films $\mathrm{Pb}_{1-\mathrm{x}} \mathrm{Mn}_{\mathrm{x}}$ Te. Thin films $\mathrm{Pb}_{1-\mathrm{x}} \mathrm{Mn}_{\mathrm{x}} \mathrm{Te}$ are obtained by the condensation of molecular beams on the support $\mathrm{BaF}_{2} x=0.01 \ldots 0.04$ (111) by varying the content of $\mathrm{Mn}$ in them. Under the incidence of plane-polarized radiation on a sample, the reflection spectrum at the angle $\varphi=10^{\circ}$ is registered by a spectrophotometer Specord-71 IR over the range $4600 \ldots 650 \mathrm{~cm}^{-1}(\lambda=2.2 \ldots 15 \mu \mathrm{m})$ at room temperature. The photoconductivity spectrum was obtained on a single-beam spectrometer IRL with the help of an optical cryostat with window through $\mathrm{BaF}_{2}$.
Irradiation of samples was conducted by $\gamma$-quanta from ${ }^{60} \mathrm{Co}$ with the dose rate $d D \gamma / d t=68.2 \mathrm{rad} / \mathrm{h}$. In addition, the absorbed dose determined by a ferrosulfate dosimeter was $D \gamma=10 \ldots 120 \mathrm{krad}$.

The IR reflection spectra of initial and $\gamma$-irradiated films $\mathrm{Pb}_{1-\mathrm{x}} \mathrm{Mn}_{\mathrm{x}}$ Te over the range under consideration $\lambda=2.2 \ldots 15 \mu \mathrm{m}$ display the occurrence of a wide band absorption in $x=4 \ldots .5 \mu \mathrm{m}$ which is related to the photosensitivity of these films in the IR region.

We have determined that the photosensitivity region under the influence of $\gamma$-radiation ( $D \gamma$ varied from 10 to $120 \mathrm{krad}$ ) drifts both to short- and longwave regions by $0.4 \ldots 0.6 \mu \mathrm{m}$ depending on the content of $\mathrm{Mn}$ in $\mathrm{Pb}_{1-\mathrm{x}} \mathrm{Mn}_{\mathrm{x}}$ Te. In addition, the intensity of this wide band changes very weakly.

The results of IR researches are maintained by the present measurements of photoconductivity, on the base of which the value of coefficient $\Delta \varepsilon g / \Delta T$ can be changed by varying the $\mathrm{Mn}$ content in $\mathrm{Pb}_{1-\mathrm{x}} \mathrm{Mn}_{\mathrm{x}} \mathrm{Te}$.

The conducted spectral researches showed that, by varying the content of $\mathrm{Mn}$, radiation-resistant experimental films $\mathrm{Pb}_{1-\mathrm{x}} \mathrm{Mn}_{\mathrm{x}}$ Te can be obtained with the properties adjusted beforehand, and photosensible diodes acting in the IR region $(x=4 \ldots 5 \mu \mathrm{m})$ can be produced on their base.

The problem of obtaining the films with perfect structure requires the selection of such substrates, whose thermal expansion coefficient (TEC) would be close to TEC of the film material. 


\section{Results and discussion}

Parameters of the substrate and film lattices will play a quite important role in this problem. The maximum possible coincidence of parameters of the lattice and the TECs of a substrate and a grown epitaxial film is strongly desired. The epitaxial films of lead chalcogenides as substrates along with $\mathrm{A}^{4} \mathrm{~B}^{6}$ usually dielectrical substrates are also used. As the most suitable dielectrical substrate for preparing the $\mathrm{PbTe}$, $\mathrm{Pb}_{1-\mathrm{x}} \mathrm{Mn}_{\mathrm{x}} \mathrm{Te}$ epitaxial films, $\mathrm{BaF}_{2}$ with the TEC $\alpha=$ $18 \cdot 10^{-4} \mathrm{deg}^{-1}$ might be served. The main advantage of dielectrical substrates is the possibility to carry out electrical isolation of separate functional elements while creating the multielement structures.

a)

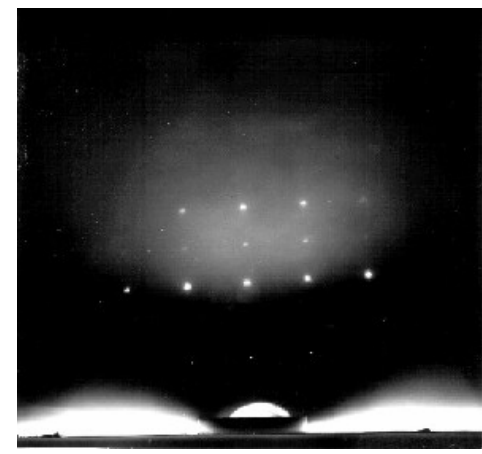

b)

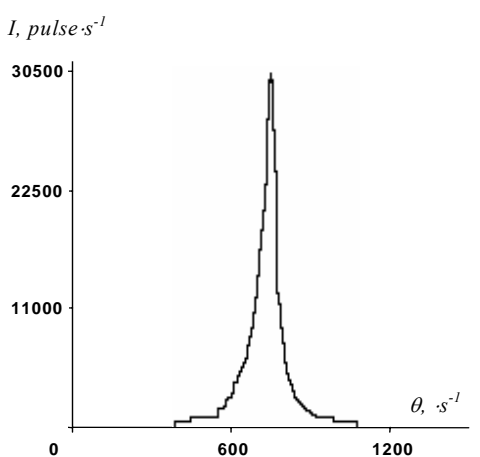

c)

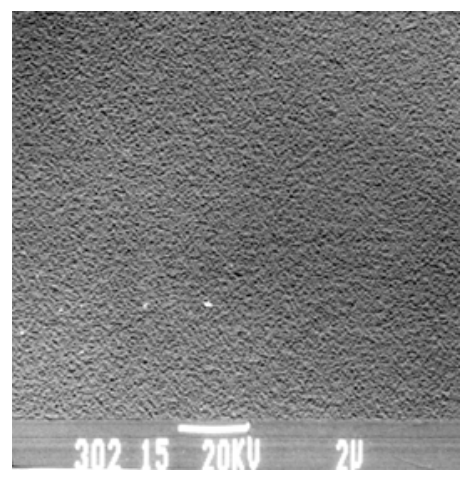

Fig. 1. Electron-diffraction picture (a), X-ray diffraction curve (b), electron microscopy picture (c) of $\mathrm{Pb}_{1-\mathrm{x}} \mathrm{Mn}_{\mathrm{x}} \mathrm{Te}(x=0.01)$ epitaxial films.
In view of the above-mentioned discussion, the aim of this work was to study the effect of electron irradiation on photoelectrical and optical properties of the $\mathrm{Pb}_{1-\mathrm{x}} \mathrm{Mn}_{\mathrm{x}} \mathrm{Te}(\mathrm{Ga}) \quad(0.01 \leq x \leq 0.05)$ epitaxial films grown on dielectrical substrates $\mathrm{BaF}_{2}$. In order to solve the posed task, the structurally perfect $\mathrm{Pb}_{1-\mathrm{x}} \mathrm{Mn}_{\mathrm{x}} \mathrm{Te}(\mathrm{Ga})$ epitaxial films with the required chemical composition, thickness, and electrophysical parameters have been obtained by the condensation of molecular beams in vacuum $10^{-4} \mathrm{~Pa}$.

The structural perfection of films was checked by electron microscopic and X-ray diffraction methods.

The crystal lattice parameters have been calculated by means of the analysis of electron-diffraction pictures and a swinging curve of X-ray diffraction. On their basis, the corresponding chemical composition of the obtained films has been determined.

The condensation rate was set by the temperature of the main source of $\mathrm{Pb}_{1-\mathrm{x}} \mathrm{Mn}_{\mathrm{x}} \mathrm{Te}(\mathrm{Ga})$. Regulating the temperature of the main and additional compensating sources allows us to obtain high-resistance films of the $n$ - and $p$-type conductivity with a concentration of $n, p$ $(77 \mathrm{~K})$ of $5 \cdot 10^{15} \ldots 2 \cdot 10^{16} \mathrm{~cm}^{-3}$ and with a charge carrier mobility $M(77 \mathrm{~K})$ equal to $2 \ldots 3 \cdot 10^{4} \mathrm{~cm}^{2} / \mathrm{V} \cdot \mathrm{s}$. The values of the mobility of charge carriers evidence also for a high perfection of the crystal lattices of the films obtained.

The study of photoelectrical properties of these films shows that they are photosensitive at the temperature of liquid nitrogen.

It has been established that the peak of the film conductivity spectrum shifts, in accordance with $[4,5]$, toward the shorter waves with increase in $x$. This is explained by increasing the forbidden zone width with increase in the manganese amount $(x=0.01 \ldots 0.05)$ in the samples under study.

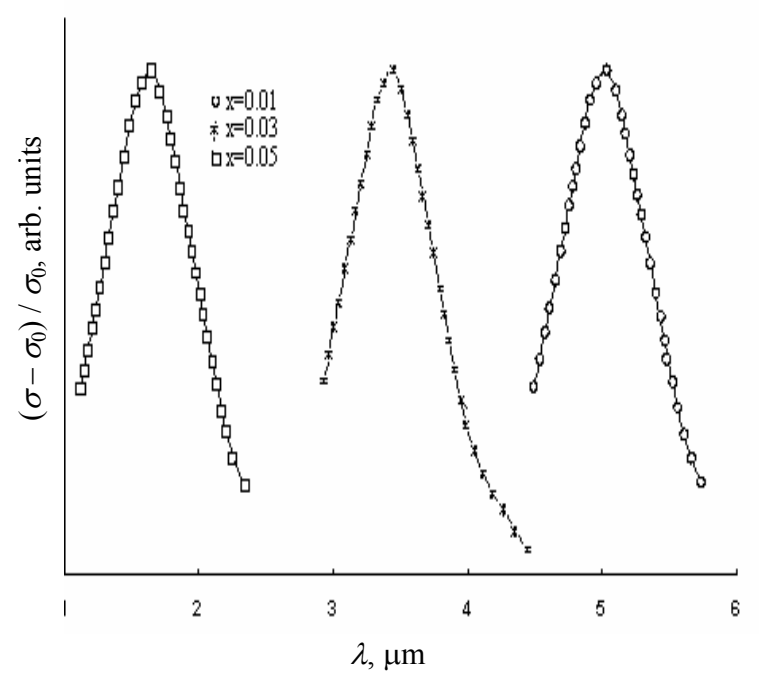

Fig. 2. Spectrum of the photoconductivity of a thin layer $\mathrm{Pb}_{1-\mathrm{x}} \mathrm{Mn}_{\mathrm{x}} \mathrm{Te}(0.01<x<0.05)$ at a temperature of $77 \mathrm{~K}$. 


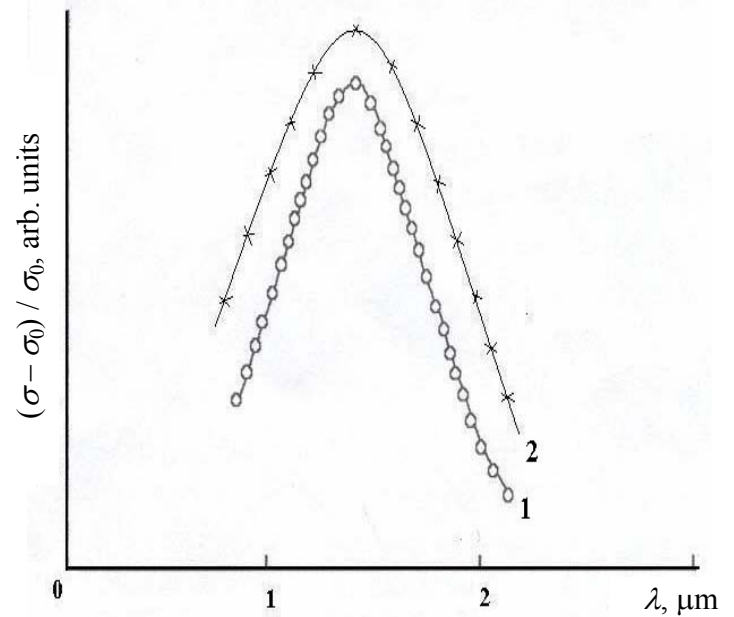

Fig. 3. Spectrum of the photoconductivity of films $\mathrm{Pb}_{1-\mathrm{x}} \mathrm{Mn}_{\mathrm{x}} \mathrm{Te}$ $(x=0.05)$ at a temperature of $77 \mathrm{~K} .1-$ a sample prior to the irradiation, 2 - after the irradiation.

We have studied the edge of optical absorption of $\mathrm{Pb}_{1-\mathrm{x}} \mathrm{Mn}_{\mathrm{x}} \mathrm{Te}(\mathrm{Ga})$ epitaxial films of different chemical compositions $\quad(0.01 \leq x \leq 0.05)$ and thicknesses $(d=1 \ldots 5 \mu \mathrm{m})$.

For the determination of the absorption coefficient $K(\lambda)$, the optical transmission $D(\lambda)$ and reflection $R(\lambda)$ coefficients have been measured.

The measurements of reflection spectra showed that the reflection coefficient $R(\lambda)$ was constant along the whole measurable IR region of the spectrum $(0 \ldots 12 \mu \mathrm{m})$ at $T=77 \ldots 300 \mathrm{~K}$.

It has been established that, with increase in the manganese content in the samples under study, the edge of the spectrum of the optical absorption coefficient shifts toward the short-wave region. This seems to be due to the increase of the forbidden zone width as a result of the Mn content growth in the samples under study as in the case of the photo-conductivity spectral dependence.

The studies of the optical absorption spectra of $\mathrm{Pb}_{1-\mathrm{x}} \mathrm{Mn}_{\mathrm{x}} \mathrm{Te}(\mathrm{Ga})$ epitaxial films of various thicknesses $(d=1 \ldots 5 \mu \mathrm{m})$ showed that the absorption coefficient was almost invariable, which was due to the high structural perfection and the mirror-smooth surface of the films obtained.

The starting samples were irradiated at $T=77 \mathrm{~K}$ with a linear electron accelerator ELU-6 $(E=5 \mathrm{MeV}$, $d \Phi / d t=10^{12} \mathrm{~cm}^{3} \cdot \mathrm{s}^{-1}, \Phi \leq 7 \cdot 10^{17} \mathrm{~cm}^{-2}$ ) [6]. The temperature dependences of the specific resistance $\rho$, concentration, and mobility of major carriers were studied for each sample prior to and after irradiation.
It has been established that, under the electron irradiation, the specific resistance $\rho$ slowly decreases at first and then increases at a temperature of $77 \mathrm{~K}$ for all studied samples. The most significant changes are characteristic of the samples with the least starting concentration of electrons.

In samples with a high starting concentration of electrons, the nature of the $\rho$ vs. $1 / T$ dependence is unaffected after irradiation. In the region of temperatures close to room one, the activation area appears related to the own ionization of charge carriers.

\section{Conclusions}

Thus, the general aim of the present work was to study the effect of electron deep irradiation on the electrophysical, photoelectrical and optical properties of unalloyed $\mathrm{Pb}_{1-\mathrm{x}} \mathrm{Mn}_{\mathrm{x}} \mathrm{Te}$ in order to determine the parameters of the energy spectrum of charge carriers for there materials and to clarify the nature of a change of their properties and, in particular, to examine the possibility to get the materials with improved properties as a result of irradiation. It has been established that, after irradiation, the samples become more photosensitive.

\section{References}

1. V.T. Trofimov, G.Z. Abbasov, G. Sprinkholts, G. Bauer, Y.Y. Zasaviskiy, Energy diagram of $\mathrm{Pb}_{1-\mathrm{x}} \mathrm{Mn}_{\mathrm{x}} \mathrm{Te} / \mathrm{PbTe}$ heterotransition // FTG 27(7), p. 1158-1164 (1993) (in Russian).

2. I.R. Nuriyev, S.S. Farzaliyev, R.M. Sadigov, Photosensitive $\mathrm{Pb}_{1-\mathrm{x}} \mathrm{Mn}_{\mathrm{x}} \mathrm{Te}(\mathrm{Ga})$ epitaxial films, in: $9^{\text {th }}$ Intern. Symposium "High pure metallic and semiconducting materials". Kharkov, Ukraine, 2126 April, 2003, p. 154-156 (in Russian).

3. I.R. Nuriyev, S.S. Farzaliyev, R.M. Sadigov, Growth of $\mathrm{Pb}_{1-\mathrm{x}} \mathrm{Mn}_{\mathrm{x}} \mathrm{Te}(\mathrm{Ga})$ epitaxial films on $\mathrm{PbTe}_{1-\mathrm{x}} \mathrm{Se}_{\mathrm{x}}$ monocrystals // Poverkhnost' 1, p. 113115 (2004) (in Russian).

4. B.A. Akimov, A.V. Nikorich, Z.Y. Ryabova, Y.M. Shirokova, Metal-dielectric transition in $\mathrm{Pb}_{1-\mathrm{x}} \mathrm{Mn}_{\mathrm{x}} \mathrm{Te}(\mathrm{In})$ solid solutions // FTG 23(6), p. 1019-1024 (1989) (in Russian).

5. E.I. Rogacheva, A.S. Sologubenko, Y.M. Krivulkin, Microhardness of $\mathrm{Pb}_{1-\mathrm{x}} \mathrm{Mn}_{\mathrm{x}} \mathrm{Te}$ semimagnetic solid solutions // Neorg. Mater. 34(6), p. 669-674 (1998) (in Russian).

6. Sh.M. Abbasov, Irradiation effect on electrophysical and optical properties of germaniumsilicium solid solutions. Elm Publ., Baku, 2003. 